\title{
Production of synthetic gasoline and diesel fuels by alternative processes using natural gas, coal and biomass: process simulation and economic analysis
}

\author{
Maria Sudiro* \\ and Alberto Bertucco \\ Department of Chemical Engineering (DIPIC), \\ University of Padova, \\ via Marzolo 9, Padova 35131, Italy \\ E-mail: maria.sudiro@unipd.it \\ E-mail: alberto.bertucco@unipd.it \\ *Corresponding author
}

\begin{abstract}
The problem of producing synthetic liquid fuels by alternative routes is addressed. Industrial processes known as Gas To Liquid (GTL), Coal To Liquid (CTL) and Biomass To Liquid (BTL) are considered: they use natural gas, coal and biomass as feedstocks, respectively. By means of process simulation, it is shown that the fuel produced on a weight basis per unit of feedstock (natural gas, coal and wood) are 66.7, 32.5 and 16.8\%, respectively; in addition, the $\mathrm{CO}_{2}$ emitted per unit mass of liquid fuel is $0.90 \mathrm{~kg} \mathrm{CO} / \mathrm{kg}$ for GTL, $4.79 \mathrm{~kg} \mathrm{CO}_{2} / \mathrm{kg}$ for CTL and $6.08 \mathrm{~kg} \mathrm{CO}_{2} / \mathrm{kg}$ for BTL process. In this last case, carbon dioxide is not an issue because it derives from a renewable source. The evaluation of production costs of synthetic fuel for a GTL process is carried out under two different scenaries: a plant localised where natural gas is readily available, and another one built far from the country where the gas is produced. A comparison between the costs of synthetic fuels from a GTL process and conventional fuel from oil refining is carried out to show the competitiveness of this alternative fuel. A financial analysis permits to conclude that, if a GTL plant is localised where the natural gas is extracted, the return of investment is after 2.4 years, whereas it changes to 6.9 years if the plant is located in western industrialised countries.
\end{abstract}

Keywords: Biomass To Liquid; BTL; Coal To Liquid; CTL; Fischer-Tropsch synthesis; FT synthesis; Gas To Liquid; GTL; gasification; synthetic fuels.

Reference to this paper should be made as follows: Sudiro, M. and Bertucco, A. (2008) 'Production of synthetic gasoline and diesel fuels by alternative processes using natural gas, coal and biomass: process simulation and economic analysis', Int. J. Alternative Propulsion, Vol. 2, No. 1, pp.13-25.

Biographical notes: Maria Sudiro obtained his degree in Chemical Engineering at the University of Padova, with the thesis: 'Alternatives fuels production for automotive purposes by synthesis processes: a technical and economical analysis' in 2005. Currently, he is a $\mathrm{PhD}$ student in Chemical Engineering at the University of Padova, (DIPIC), third year. Thesis' title is: 'Alternative processes for the production of liquid fuels: development and simulation'. Also he is working about the development of new processes of producing synthetic fuels from coal and biomasses, with a detailed modelling. $\mathrm{He}$ is carrying out experiments about bioethanol fermentation under $\mathrm{CO}_{2}$ pressure. In 2006, she has been involved in the design of the first bioethanol plant in Italy

Copyright (C) 2008 Inderscience Enterprises Ltd. 
Alberto Bertucco is a full professor of Chemical Engineering at the University of Padova. During 25 years of his university career, he has developed research activities in four fields: online control of distillation units, thermodynamics of fluid phase equilibria of multicomponent mixtures, extractive and nonextractive applications of supercritical fluids, simulation of petroleum and petrochemical industrial processes. He has published 110 scientific papers, 86 of which in international refereed journals. From 2004, he has started research activity in the field of alternative fuels. In 2006, he has been involved in the design of the first bioethanol plant in Italy.

\section{Introduction}

In the 20th century, the use of petroleum dominated the process industries and with it came the birth and growth of chemical engineering and chemical technology. Now, we are beginning to realise that the world's petroleum reserves are not infinite. Because they are rapaciously being consumed, their costs are rising and sooner or later a time will come when we will have to look for a replacement of petroleum. Oil price variation from 1940 to 2006 is from 12 to $75 \$ /$ barrel, a value corrected by using standard devaluation index (http://research.stlouisfed.org/fred2/series/OILPRICE/98/10yrs).

Nowadays, fuels from crude oil supply about $96-98 \%$ of the worldwide energy demand for transportation (cars, ships and airplanes) and more than $50 \%$ of oil extracted is refined to produce fuels. Estimates of the oil availability span from 40 to 60 years at the present rate of consumption (www.ifp.fr).

On the other hand, the currently known reserves of methane and of coal exceed those of crude oil by factors of about 1.5 and 25, respectively (Dry, 2002). Production of syngas from methane or coal or biomass, and successive conversion of the syngas to a range of fuels and chemicals could become increasingly of interest as the reserves of crude oil are depleted and/or the price of crude rises.

The perspective for a final solution of the energy source problem is not shorter than 50 years. So, for transportation purposes liquid synthetic fuels with high volumetric density of energy are likely to be produced using alternative technologies in the transition time between now and then.

Alternatives to fossil fuels are biofuels (bioethanol and biodiesel), hydrogen (even if this is currently obtained from hydrocarbons) and synthetic fuels.

Aim of this work is an evaluation of the technical and economic feasibility of a number of processes of production of synthetic fuels.

Three processes have been addressed and examined by process simulation: they are referred to as Gas To Liquid (GTL), Coal To Liquid (CTL) and Biomass To Liquid (BTL).

\section{Model simulation}

The models of the three processes considered (GTL, CTL and BTL) were developed using Aspen Plus ${ }^{\mathbf{T M}}$ as process simulator. Material and energy balances were accounted for and solved for every process unit, whereas no chemical kinetic models were 
considered in reactor simulation. The plant capacity was $100 \mathrm{t} \mathrm{h}^{-1}$ of liquid fuel (gasoline, diesel and GPL, with a weight composition of about 1, 29 and 70\%, respectively), starting from natural gas, coal and wood as feedstocks.

Synthetic fuels process routes consist of five sections at least: syngas production and purification, Fischer-Tropsch (FT) synthesis, hydrocracking, separation of products, water treatment and recycle. All of them were simulated as detailed in the following section.

\subsection{Thermodynamic model}

Both for reactors and separators the selection of a suitable thermodynamic model is of paramount importance. For the mixtures involved in GTL, CTL and BTL processes both equations of state and $\mathrm{g}^{\mathrm{E}}$ models were used.

The Peng-Robinson equation of state with Boston-Mathias alpha function was applied in the main units (reactors, distillation columns and two phase separators).

In separation, sections involving also liquid-liquid-vapour three-phase systems, these equilibra have been represented by the Non-Random Two Liquid (NRTL) equation (Poling et al. 2000). In particular, this detailed thermodynamic model has been useful in the section of water treatment: the water produced from FT synthesis contains oxygenated compounds, with the composition given in Table 1. Ten compounds have been chosen to describe this mixture: methanol, ethanol, 1-propanol, 1-butanol, 1pentanol, 1-hexanol, acetic acid, propionic acid, butyric acid and water; alcohols higher than $\mathrm{C}_{6}$ and acids higher than $\mathrm{C}_{4}$ were neglected.

The NRTL equation used in Aspen Plus ${ }^{\mathrm{TM}}$ is:

$$
\ln \gamma_{i}=\frac{\sum_{j} x_{j} \tau_{j i} G_{j i}}{\sum_{k} x_{k} G_{k i}}+\sum_{j} \frac{x_{j} G_{i j}}{\sum_{k} x_{k} G_{k j}}\left(\tau_{i j}-\frac{\sum_{m} x_{m} \tau_{m j} G_{m j}}{\sum_{k} x_{k} G_{k j}}\right)
$$

where $G_{i j}=\exp \left(-a_{i j} \tau_{i j}\right)$

$\tau_{i j}=a_{i j}+b_{i j} / T+\mathrm{e}_{i j} \ln T+f_{i j} T, a_{i j}=\mathrm{c}_{i j}+d_{i j}(T-273.15 \mathrm{~K}), \tau_{i i}=0$ and $G_{i i}=0$.

For the pairs of components with missing parameters in Aspen Plus ${ }^{\mathrm{TM}}$, we have assumed that: the system 1-pentanol-acetic acid has same parameters as the system 1-butanol-acetic acid; the systems methanol, ethanol, 1-propanol, 1-butanol, 1-pentanol, 1-hexanol with propionic acid and butyric acid have same parameters as the corresponding systems methanol, ethanol, 1-propanol, 1-butanol, 1-pentanol, 1-hexanol with acetic acid; for the system propionic acid-butyric acid the binary parameters have been set to zero. In Table 2, the matrix of all pairs of components is shown with the indication on how binary parameters were defined. Experimental data were retrieved from literature for the systems: ethanol-acetic acid and butanol-acetic acid (Rius et al., 1959), hexanol-acetic acid (Apelblat et al. 1983), water-acetic acid and water-propionic acid (Ito and Yoshida, 1963), acetic acid and propionic acid (Tamir and Wisniak, 1975).

Values of binary NRTL interaction parameters are summarised in Table 3. 
Table 1 Experimental composition of water produced from Fischer-Tropsch synthesis

\begin{tabular}{lclclc}
\hline Compounds & Weight $(\mathrm{ppm})$ & Compounds & Weight $(\mathrm{ppm})$ & Compounds & Weight $(\mathrm{ppm})$ \\
\hline Methane & 0 & Ethanol & 2,520 & 1-Decanol & 10 \\
n-Pentane & 70 & 1-Propanol & 2,300 & 1-undecanol & 0 \\
n-Hexane & 20 & 1-Butanol & 1,720 & Acetic acid & 1,010 \\
Carbon dioxide & 0 & 1-Pentanol & 1,000 & Propionic acid & 690 \\
1-Pentene & 200 & 1-Hexanol & 480 & Butyric acid & 340 \\
1-Hexene & 70 & 1-Heptanol & 210 & Pentanoic acid & 100 \\
1-Heptene & 20 & 1-Octanol & 80 & Hexanoic acid & 20 \\
Methanol & 2380 & 1-Nonanol & 30 & Acetone & 50 \\
\hline
\end{tabular}

Table 2 Matrix of Non-Random Two Liquid binary parameters

\begin{tabular}{|c|c|c|c|c|c|c|c|c|c|c|}
\hline & 1 & 2 & 3 & 4 & 5 & 6 & 7 & 8 & 9 & 10 \\
\hline 1 & & A & A & A & A & A & A & $\mathrm{C}$ & $\mathrm{C}$ & A \\
\hline 2 & & & A & A & A & A & B & $\mathrm{C}$ & $\mathrm{C}$ & A \\
\hline 3 & & & & A & A & A & A & A & $\mathrm{C}$ & A \\
\hline 4 & & & & & A & A & B & $\mathrm{C}$ & $\mathrm{C}$ & A \\
\hline 5 & & & & & & A & $\mathrm{C}$ & $\mathrm{C}$ & $\mathrm{C}$ & A \\
\hline 6 & & & & & & & B & $\mathrm{C}$ & $\mathrm{C}$ & A \\
\hline 7 & & & & & & & & B & $\mathrm{C}$ & B \\
\hline 8 & & & & & & & & & $\mathrm{O}$ & B \\
\hline 9 & & & & & & & & & & A \\
\hline 10 & & & & & & & & & & \\
\hline
\end{tabular}

A, Aspen Plus; B, Regressed; C, Assumed; O, Zero; 1, Methanol; 2, Ethanol; 3, 1-Propanol; 4, 1-Butanol; 5, 1-Pentanol; 6, 1-Hexanol; 7, Acetic acid; 8, Propionic acid; 9, Butyric acid and 10, Water.

Table 3 Non-Random Two Liquid parameters fitted from Vapour Liquid Equilibrium experimental data

\begin{tabular}{lcccccc}
\hline Comp. $i$ & Ethanol & Butanol & Hexanol & Water & Water & Acetic acid \\
\hline Comp. $j$ & Acetic acid & Acetic acid & Acetic acid & Acetic acid & Propionic acid & Propionic acid \\
\hline T & $\mathrm{K}$ & $\mathrm{K}$ & $\mathrm{K}$ & $\mathrm{K}$ & $\mathrm{K}$ & $\mathrm{K}$ \\
aij & 19.6716 & 36.283 & 423.79 & -7.0904 & -23.261 & -22.116 \\
aji & -7.9712 & -23.398 & 195.08 & 6.1332 & 8.6653 & -68.108 \\
Bij & -7136.3 & -5236.0 & -90000 & -3364.3 & 9226.9 & 8522.0 \\
Bji & 2757.3 & 115.38 & -58459 & 4289.1 & -2429.7 & 29195 \\
cij & 1.2568 & $8.4182 \times 10^{-4}$ & 0.0371 & $4.1906 \times 10^{-3}$ & 0.7816 & 0.4069 \\
\hline
\end{tabular}


Table 4 Non-conventional solid compositions defined in Aspen Plus

\begin{tabular}{lccccccc}
\hline & \multicolumn{7}{c}{ Proxanal $(\% w t)$} \\
\hline & Coal & Wood & Ash & & Coal & Wood & Ash \\
Water & 2.2 & 15 & - & C & 72.24 & 50.1 & 0 \\
$\begin{array}{l}\text { Volatile } \\
\text { matter }\end{array}$ & 32.7 & - & - & H & 4.14 & 6.12 & 0 \\
$\begin{array}{l}\text { Fixed } \\
\text { carbon }\end{array}$ & 51.3 & - & - & N & 1.72 & 41.9 & 0 \\
Ash & 13.8 & 1.39 & 100 & S (organic) & 0.86 & 0 & 0 \\
& - & - & - & O & 7.24 & 0.49 & 0 \\
& - & - & - & Ash & 13.8 & 1.39 & 100 \\
\hline
\end{tabular}

\subsection{Definition of hydrocarbons and gas components}

The following compounds have been selected from the Aspen Plus ${ }^{\mathrm{TM}}$ databank: $\mathrm{O}_{2}, \mathrm{~N}_{2}$, $\mathrm{CO}, \mathrm{CO}_{2}, \mathrm{H}_{2}, \mathrm{H}_{2} \mathrm{O}, \mathrm{H}_{2} \mathrm{~S}$, ethanol, methane, ethylene, ethane, propylene, propane, butene, butane and all the linear and saturated hydrocarbon from $\mathrm{C}_{5} \mathrm{H}_{11}$ to $\mathrm{C}_{30} \mathrm{H}_{62}, \mathrm{C}_{32} \mathrm{H}_{66}$ and $\mathrm{C}_{36} \mathrm{H}_{74}$.

Besides, other compounds between $\mathrm{C}_{37}$ and $\mathrm{C}_{60}$ have been added to describe rigorously products of FT synthesis: $\mathrm{C}_{37} \mathrm{H}_{76}, \mathrm{C}_{38} \mathrm{H}_{78}, \mathrm{C}_{39} \mathrm{H}_{80}, \mathrm{C}_{40} \mathrm{H}_{82}, \mathrm{C}_{45} \mathrm{H}_{92}, \mathrm{C}_{50} \mathrm{H}_{102}$, $\mathrm{C}_{55} \mathrm{H}_{112}$ and $\mathrm{C}_{60} \mathrm{H}_{122}$. For them, a minimum number of properties were introduced into the simulator: vapour pressure (API tables), density, molecular weight, normal boiling point and critical constants (Joback model). Critical volume, critical compressibility factor and standard enthalpy of formation have been estimated.

Finally, non-conventional solids have been defined to describe coal, wood and ash, whose compositions are tabulated in Table 4 (Higman and Van Der Burgt, 2003). For these components two models must be defined: one for density (DCOALIGT) and one for enthalpy (HCOALGEN), which requires to specify proximate analysis and ultimate analysis of the solids.

\subsection{Definition of blocks}

As far as syngas formation is concerned, in the GTL process they are produced by autothermal reforming while in CTL and BTL processes both a gasifier reactor and a water gas shift reactor are required.

An equilibrium model (RGibbs) has been used in the case of GTL process taking into account the reactions:

$$
\begin{aligned}
& \mathrm{CH}_{4}+\mathrm{H}_{2} \mathrm{O} \leftrightarrow 3 \mathrm{H}_{2}+\mathrm{CO} . \\
& \mathrm{CO}+\mathrm{H}_{2} \mathrm{O} \leftrightarrow \mathrm{H}_{2}+\mathrm{CO}_{2} .
\end{aligned}
$$

For CTL and BTL processes, the gasifier was represented by two units: a RYield reactor and a RGibbs adiabatic rector. In the first one coal (as well as biomass) is broken down into their elements $\mathrm{H}_{2}, \mathrm{~N}_{2}, \mathrm{O}_{2}, \mathrm{~S}, \mathrm{C}$ (solid), ash and water as moisture, whereas in the 
second unit reactions (2) and (3) occur. After gasification cyclones and baghouse filters separate ash from the gaseous stream. Finally, water and $\mathrm{CO}_{2}$ are removed in a flash unit.

FT synthesis was modelled by using a RYield reactor. The experimental products distribution is known (Oukaci, 2005) and syngas conversion is assumed equal to $87 \%$ (Moulijn, Makkee and Diepen, 2003).

FT reactions are summarised as:

$$
\begin{aligned}
& n \mathrm{CO}+(2 n+1) \mathrm{H}_{2} \rightarrow \mathrm{C}_{n} \mathrm{H}_{2 n+2}+n \mathrm{H}_{2} \mathrm{O} \quad(n \text { - paraffins). } \\
& n \mathrm{CO}+2 n \mathrm{H}_{2} \rightarrow \mathrm{C}_{n} \mathrm{H}_{2 n+1} \mathrm{OH}+(n-1) \mathrm{H}_{2} \mathrm{O} \quad \text { (alcohols). }
\end{aligned}
$$

Overall, 44 reactions of these types were written for all compounds from $\mathrm{CH}_{4}$ to $\mathrm{C}_{60} \mathrm{H}_{122}$ and ethanol.

Figure 1 shows the simulated products distribution, that is in acceptable agreement with the experimental profile. Product distribution on a weight basis is: gasoline $\left(\mathrm{C}_{5}\right.$ to $\left.\mathrm{H}_{11}\right) 25.6 \%$, diesel $\left(\mathrm{C}_{12}\right.$ to $\left.\mathrm{H}_{18}\right) 40.3 \%$, waxes $\left(\mathrm{C}_{19}\right.$ to $\left.\mathrm{H}_{60}\right) 31.6 \%$, light gases $1.6 \%$ and oxygenated compounds $1 \%$.

The hydrocracking reactor was modelled using a RYield reactor, where product yields have been calculated assuming a conversion of the heavy feed (waxes) of $80 \%$ while the unreacted $20 \%$ is recycled to the reactor, after products separation. $\mathrm{H}_{2}$ used in this section is $0.65 \%$ of the heavy feed (Nasti, 2005). Waxes are converted to diesel ( $80 \%$ by weight), gasoline (15\%) and to gaseous compounds: light hydrocarbons such as methane, ethane, propane and butane (5\%), (Tijmensen, 2002).

Products separation from FT reactor outlet was achieved by four columns. The first one uses direct injection of steam and has a lateral stripper to recover the diesel fraction; here, the bottom product contains waxes while gaseous compounds and gasoline areextracted from the top. The bottom is sent to the hydrocracking reactor and the products of the reactor are sent to a second column similar to the first one, with direct injection of steam and a lateral stripper to recover the diesel fraction. The bottom is recycled to hydrocracking reactor and the top is sent, with the top of the other column to two column in series, in order to recover GPL and gasoline products.

Figure 1 Products distribution (calculated and experimental) at the output of the Fischer-Tropsch reactor (see online version for colours)

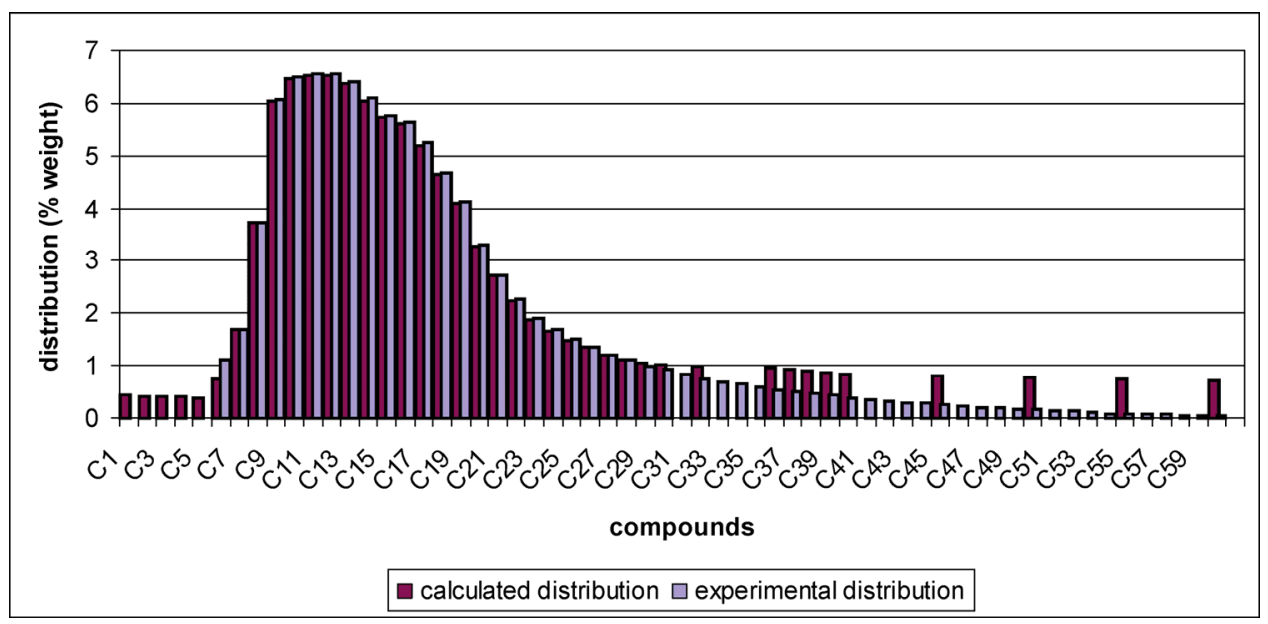


Water at the output of the FT reactor amounts to $48.4 \%$ of all products (weight basis) and contains many polluting compounds (alcohols and organic acids overall 1.3\%). A stripping column was used to treat this water, with steam and partial condenser: the gaseous stream at the top contains $65.7 \%$ on weight basis of oxygenated compounds and the bottom product is without alcohols but contains some acids.

\section{Simulation results and discussion}

Block flow diagrams of the simulated process: GTL, CTL and BTL are reported, respectively, in Figures $2-4$, where all flow rates are also shown to check material balances.

The fuel production per unit of feedstock (natural gas, coal and wood, weight basis), is $66.7,32.5$ and $16.8 \%$, respectively; these values are in agreement with data from industrial and pilot plants.

Synthetic fuels produced from the three processes have always a similar proportion: GPL 1\%, gasoline 29\% and diesel $70 \%$.

Figure 2 Block flow diagram of the Gas To Liquid process

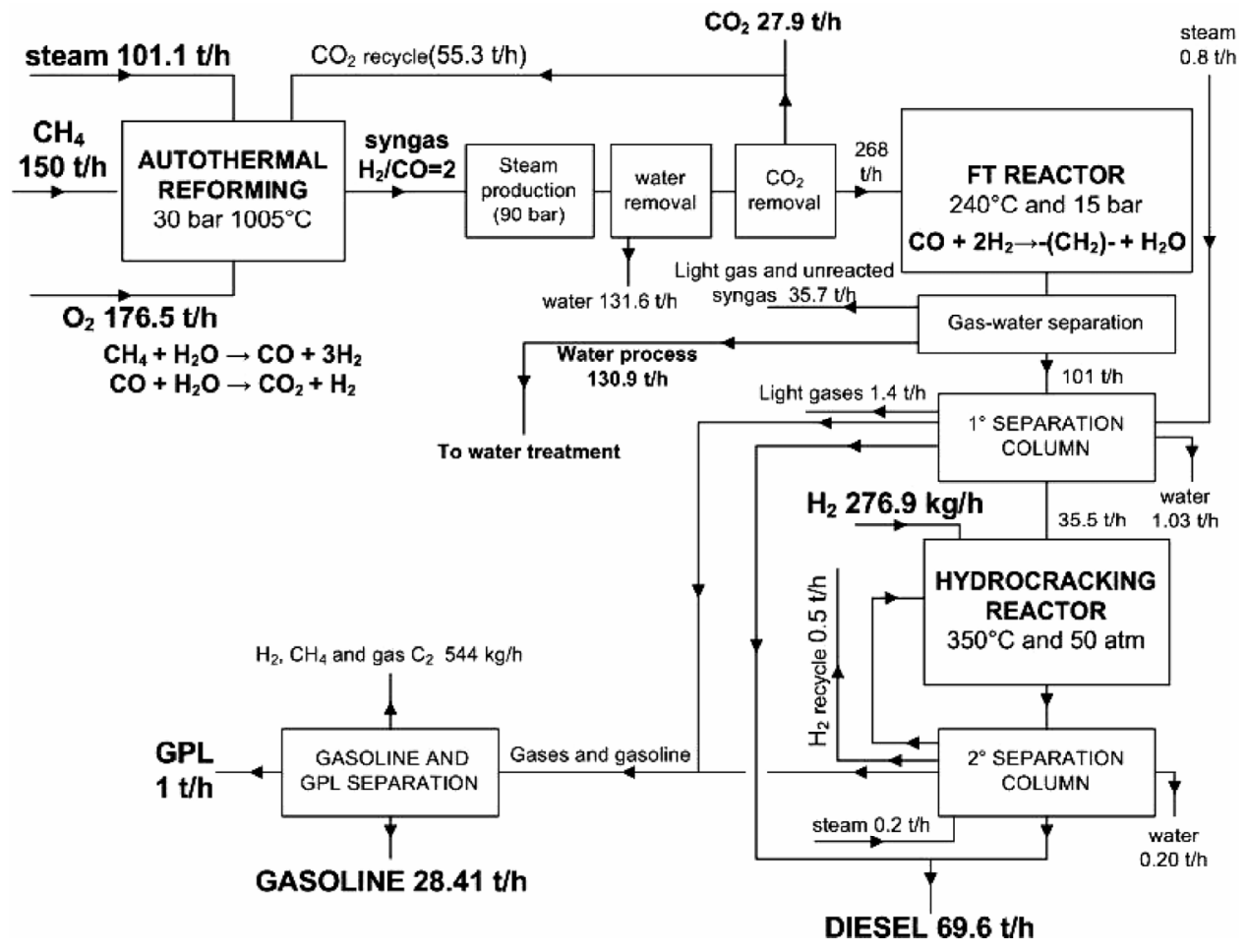


Figure 3 Block flow diagram of the Coal To Liquid process

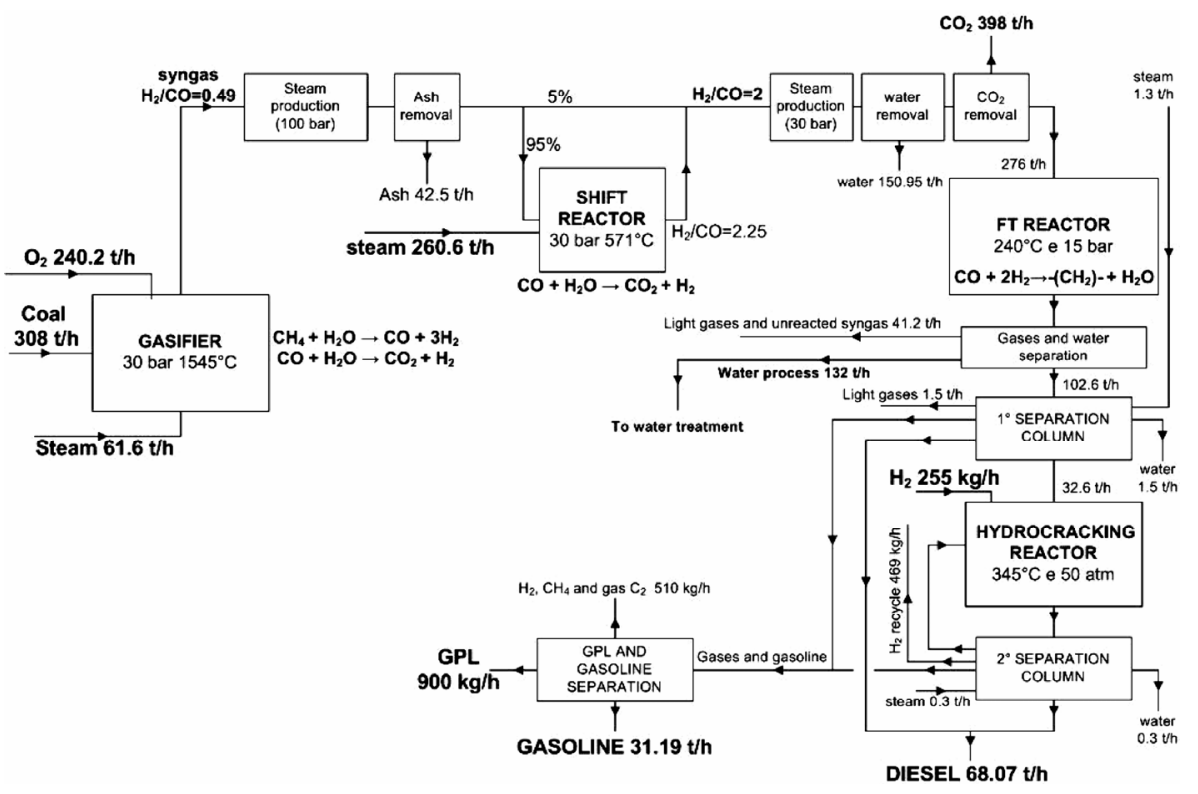

Figure 4 Block flow diagram of the Biomass To Liquid process

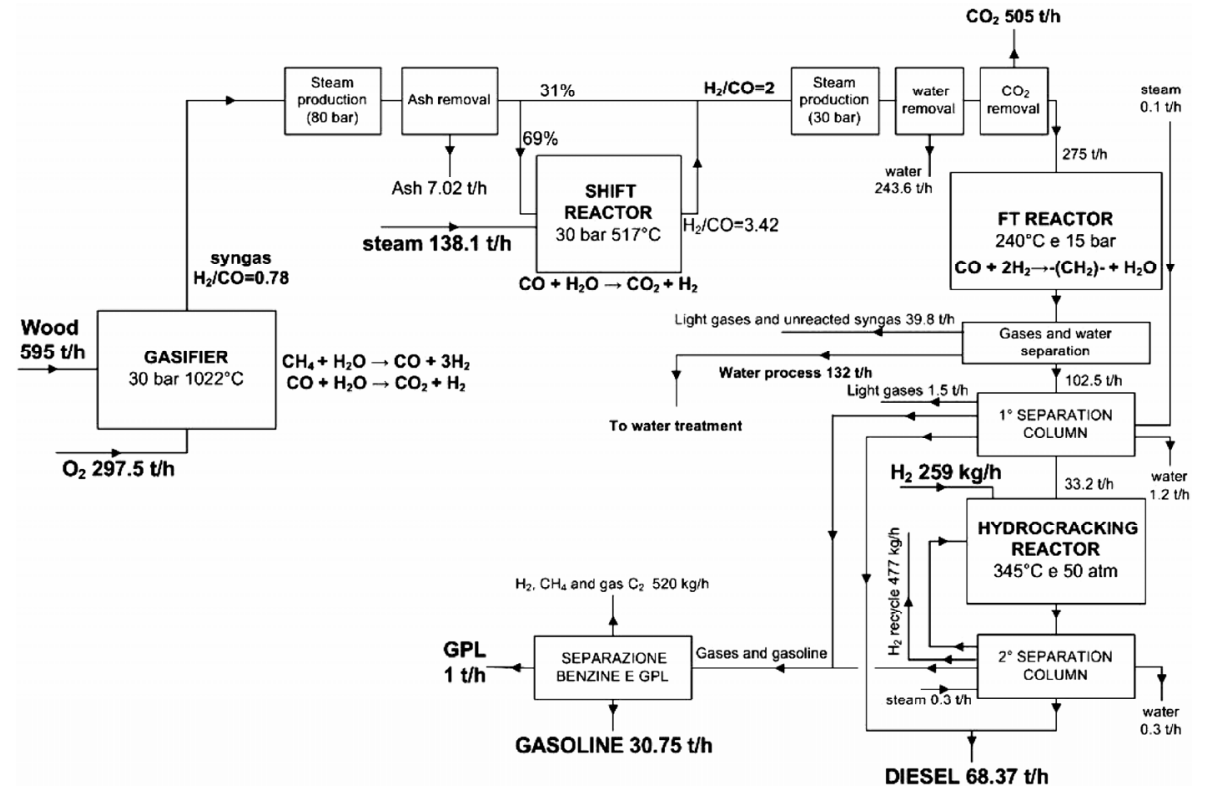

In addition, the $\mathrm{CO}_{2}$ produced per unit mass of liquid fuel is $0.90 \mathrm{~kg} \mathrm{CO} / \mathrm{kg}$ for GTL, $4.79 \mathrm{~kg} \mathrm{CO} 2 / \mathrm{kg}$ for CTL and $6.08 \mathrm{~kg} \mathrm{CO}_{2} / \mathrm{kg}$ for BTL process. In this last case, carbon dioxide is not an issue because it derives from a renewable source. We remember that when the fuel is burnt in the car engine about $3 \mathrm{~kg} \mathrm{CO}_{2} / \mathrm{kg}$ fuel are produced in addition. 
Figure 5 Partitioning of the investment costs for a Gas To Liquid plant (see online version for colours)

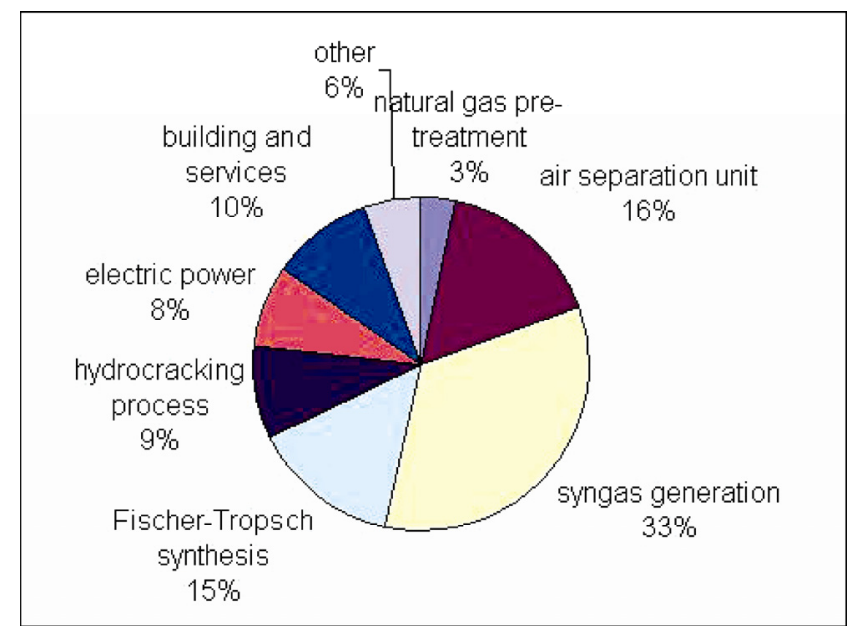

We recall that in a steam reforming industrial plant producing hydrogen from $\mathrm{CH}_{4}$ about $9 \mathrm{~kg} \mathrm{CO}$ are obtained per $\mathrm{kg}$ of $\mathrm{H}_{2}$ produced (Nasti, 2005), comparable to the CTL case.

From the energy analysis it can be concluded that the GTL process is energetically self-sufficient.

In a similar way, energy integration has been carried out for CTL process with the same conclusion.

Also, after the energy integration of the two processes, the $\mathrm{CO}_{2}$ emissions have been recalculated and for GTL are $0.63 \mathrm{~kg} \mathrm{CO}_{2} / \mathrm{kg}$ synfuel produced and for CTL are $4.66 \mathrm{~kg}$ $\mathrm{CO}_{2} / \mathrm{kg}$ synfuel produced (Sudiro and Bertucco, 2007).

\section{Economic and financial analysis}

The cost of production of synthetic fuels from a GTL process was calculated and the return of investment was evaluated.

For CTL and BTL processes, this analysis could not be carried out due to the lack of data for the estimation of the operating and investment costs; in fact, only pilot plants of these types are currently operated in the world.

\subsection{Economic analysis}

The minimum capacity of a GTL plant corresponds to two air separation units, needed to obtain $\mathrm{O}_{2}$, that is for a production from 34,000 to 36,000 barrels per day (bpd) of liquid fuel (Steynberg and Dry, 2004). This capacity is obtained with two trains of equipments, each one including one air separation unit, one reforming reactor and one FT synthesis reactor, and producing $100 \mathrm{t} \mathrm{h}^{-1}$ of synthetic fuel.

The partitioning of the investment costs for a GTL plant of 34,000 bpd capacity is shown in Figure 5.

Capital cost is about 25,000 $\$ \mathrm{bpd}^{-1}$ (Steynberg and Dry, 2004) and resulting operating cost, without considering devaluation and feedstock cost, is 4-6\$ per barrel of product. 
To determine the cost of production of synthetic fuel the natural gas cost is needed. Natural gas price is $10-14 \$ \mathrm{Gcal}^{-1}$ in the developed country, where it is imported, and $2 \$ \mathrm{Gcal}^{-1}$ where it is directly extracted; with a heating value of $12,000 \mathrm{kcal} \mathrm{kg}^{-1}$ the cost becomes $0.12-0.17 \$ \mathrm{~kg}^{-1}$ in the first case and $0.024 \$ \mathrm{~kg}^{-1}$ in the second one. We remember that $1.5 \mathrm{~kg}$ natural gas are needed to produce $1 \mathrm{~kg}$ of liquid fuel, according to our simulation.

Table 5 summarises capital, operating and feedstock costs and the final production fuel cost. It is clear how for plant far from the country of natural gas extraction (Case 1) the main cost is feedstock, about five times of the capital cost; for this reason GTL plants will be conveniently located in the country where the gas is available (Case 2).

\subsection{Fossil fuels and synthetic fuels comparison}

It is interesting to compare the synthetic fuel cost with that of fossil fuel. The last can be easily (and roughly) evaluated on the base of the oil barrel price.

The cost of production of fossil fuel can be estimated equal to $0.349 € 1^{-1}, 0.439 € 1^{-1}$ and $0.549 € \mathrm{1}^{-1}$, respectively, for a price of barrel of 63.54 (as at November 30, 2006) (www.24oreborsaonline.ilsole24ore.com), 80 and 100 US dollars.

The comparison with synthetic fuel is shown in Figure 6, where it is clear the competitiveness of the synthetic fuel: where the plant is located close is the feedstock the advantage is 3.5 times at the current oil price.

Table 5 Total cost of production of synthetic fuel from a Gas To Liquid plant in two different scenaries

\begin{tabular}{|c|c|c|}
\hline Costs & Case 1 & Case 2 \\
\hline Capital cost (Million \$) & 85 & 85 \\
\hline Operating cost (Million \$) & 74.256 & 74.256 \\
\hline Natural gas cost (Million \$) & 445.536 & 62.899 \\
\hline Total (Million \$) & 604.792 & 222.155 \\
\hline Cost of production of one barrel (\$) & 48.87 & 17.95 \\
\hline Cost of production of one liter of liquid fuel (\$) & 0.308 & 0.113 \\
\hline Cost of production of one liter of liquid fuel $(€)$ & 0.234 & 0.086 \\
\hline
\end{tabular}

Figure 6 Comparison between cost of production of synthetic fuel (case 1 and 2) with fossil fuel (see online version for colours)

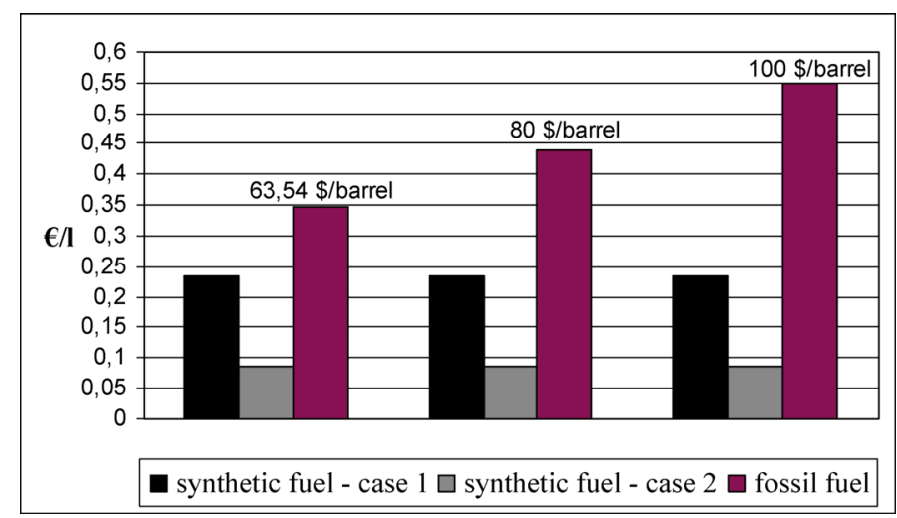




\subsection{Financial analysis}

To do a financial analysis we have calculated the Net Present Value (NPV), that is the sum of discounted free cash flow and the Internal Rate of Return (IRR), which represents the interest rate received for an investment.

In order to carry out a financial analysis it is necessary to set the tax rate and the discount rate. We selected $35 \%$ for the first one and $15 \%$ for the second one.

Then the market price of the alternative fuel must be known. It is known that this fuel in Europe has a market price of $500 \$ \mathrm{t}^{-1}$ (Nasti, 2005) and assuming a medium value of density of $0.8 \mathrm{t} \mathrm{m}^{-3}$, the result is $0.4 \$ \mathrm{l}^{-1}$ of diesel synthetic fuel. This value becomes $(0.303 €$ with the current $\$$ to $€$ exchange rate (November 30, 2006)) (www.24oreborsaonline.ilsole24ore.com).

We distinguish between two cases:

1 the plant is located far away from the country of origin of the raw materials

2 the plant is located near the gas extraction site.

A sensitivity analysis on the capital cost in the range $25,000-30,000 \$ \mathrm{bpd}^{-1}$ has also been done.

Results are tabulated in Table 6 where case 1 is for a plant located far away from the country of origin of natural gas (natural gas cost of $0.17 \$ \mathrm{~kg}^{-1}$ ), case 2 is for a plant located near the extraction of natural gas, where it is cheaper. Cases $3 \mathrm{a}$ and $3 \mathrm{~b}$ correspond to cases 1 and 2 but with capital costs equal to $30,000 \$$ bpd $^{-1}$.

Table 6 Financial analysis results

\begin{tabular}{lcccc}
\hline & Case 1 & Case 2 & Case 3a & Case 3b \\
\hline IRR (\%) & 20.06 & 52.38 & 15.76 & 43.67 \\
NPV (Million \$) & 169.75 & 1417.987 & 29.612 & 1277.849 \\
Time necessary to repay the plant (years) & 6.9 & 2.4 & 9.3 & 3 \\
& & & & \\
\hline
\end{tabular}

Figure 7 Cumulative discounted cash flow vs. years in the four cases examined (see online version for colours)

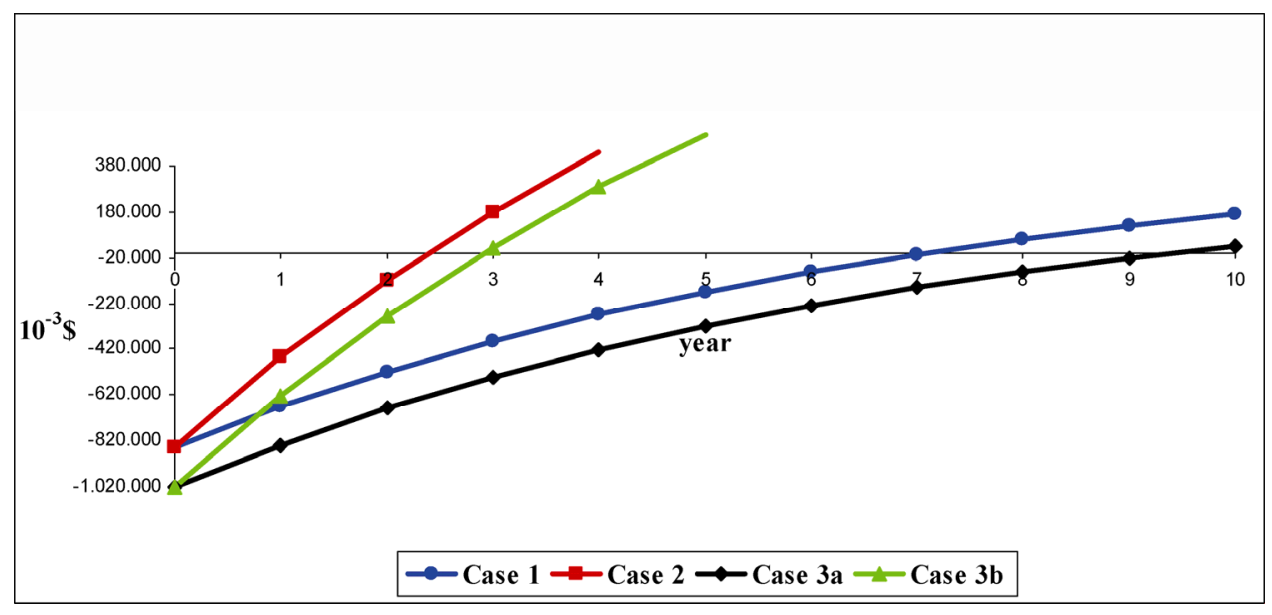


Figure 7 shows cumulative discounted cash flow vs years in the four cases examined.

These results confirm the fundamental role of feedstock cost for the convenience of a GTL plant: if it is built in a country where natural gas is available at a low price, also in the more unfavourable hypothesis, the return of the investment is of approximately 3 years. In developed countries this value increases to about 9 years.

\section{Conclusions}

A detailed process simulation was developed for three $100 \mathrm{th}^{-1}$ synthetic fuel production plants from three different feedstocks: natural gas, coal and wood. Corresponding processes are named GTL, CTL and BTL. Product yields (weight basis) of 66.7, 32.5 and $16.8 \%$ were found, respectively.

The $\mathrm{CO}_{2}$ emitted for unit mass of liquid fuels produced is $0.90 \mathrm{~kg} \mathrm{CO}_{2} / \mathrm{kg}$ for GTL, $4.79 \mathrm{~kg} \mathrm{CO} / \mathrm{kg}$ for $\mathrm{CTL}$, and $6.08 \mathrm{~kg} \mathrm{CO}_{2} / \mathrm{kg}$ for BTL process. In this last case, $\mathrm{CO}_{2}$ is neutral, because it derives from a renewable source.

The economical and financial analysis has shown that it is extremely convenient to invest in a GTL plant located in countries where natural gas is available at a low price, thanks to the favourable return of investment.

No such analysis could be carried out for both the CTL and BTL processes, as only pilot plants are currently operated around the world in these cases.

\section{References}

Apelblat, A., Tamir, A. and Wagner, M. (1983) 'Association in carboxylic acid-aliphatic alcohol mixtures: the binary mixtures of acid acetic with n-butanol, n-hexanol, n-octanol and n-dodecanol', Zeitschrift für Physikalische Chemie (Wiesbaden), Vol. 137, pp.129-137.

Dry, M.E. (2002) 'The Fischer-Tropsch process: 1950-2000', Catalysis Today, Vol. 71, pp.227-241.

Energy Consumption and Oil Availability. Available at: www.ifp.fr.

Euro-Dollar Exchange Rate. Available at: www.24oreborsaonline.ilsole24ore.com.

Higman, C. and Van Der Burgt, M. (2003) Gasification. Burlington, MA: Gulf Professional Publishing Elsevier.

Ito, T. and Yoshida, F. (1963) 'Vapor-liquid equilibra of water-lower fatty acid systems: water-formic acid, water-acetic acid and water-propionic acid', Journal of Chemical Engineering, Data., Vol. 8, pp.315-320.

Moulijn, J.A., Makkee, M. and Diepen, A. V. (2003) Chemical Process Technology. Chirchester, UK: Jon Wiley and Sons, Ltd.

Nasti (2005) 'Independent consultant', Personal Communications.

Oukaci, R. (2005). 'Fischer-Tropsch synthesis', Presented at the 5th Annual World GTL Conference. London, UK, May 17.

Oil price variation from 1940 to now. Available at: http://research.stlouisfed.org/fred2/series/ OILPRICE/98/10yrs.

Poling, B.E., Prausnitz, J.M. and O'Connel, J.P. (2000) The properties of gases and liquids (5th ed.). New York, NY: McGraw-Hill.

Rius, A., Otero, J. L. and Macarron, A. (1959) 'Equilibres liquide-vapeur de mélanges binaires donnant une réaction chimique; systèmes méthanol-acide acétique; éthanol-acide acétique; n-propanol-acide acétique; n-butanol-acide acétique', Chemical Engineering Science, Vol. 10, pp.105-111; 288-290. 
Tamir, A. and Wisniak, J. (1975) 'Vapour-liquid equilibra in associating solutions', Chemical Engineering Science, Vol. 30, pp.335-341.

Tijmensen M.J.A., Faaij, A.P.C., Hamelinck, C.N. and Van Hardeveld, M.R.M. (2002) 'Exploration of the possibilities for production of Fischer-Tropsch liquids and power via biomass gasification', Biomass and Bioenergy, Vol. 23, pp.129-152.

Steynberg, A.P. and Dry, M.E. (2004) Fischer-Tropsch Technology. Amsterdam, The Netherlands: Elsevier.

Sudiro, M. and Bertucco A. (2007). 'Production of synthetic gasoline and diesel fues by alternative processes using natural gas and coal: process simulation and optimization', Paper presented in the Proceedings of the ECOS07 20st International Conference on Efficiency, Cost, Optimization, Simulation and Environment Impact of Energy Systems, Padova (Italy), 25-28 June, 2007. Vol. II, pp.1361-1368. 